\title{
Blog as an Online Assessment: Exploring Students' Experiences of It
}

\author{
Fitriah \\ English Language Education Department \\ UIN Sunan Ampel \\ Surabaya, Indonesia \\ fitriahasad@gmail.com
}

\author{
Kharisatur Rofiqo \\ English Language Education Department \\ UIN Sunan Ampel \\ Surabaya, Indonesia \\ rofiqokharisatur25@gmail.com
}

\begin{abstract}
Assessment is a fundamental process to identify the students' progress and achievement in language learning. Teachers can measure the successful of teaching and recognize the students' strengths and weaknesses from the result of assessment. Nowadays, teachers do not need to come to the classroom to assess the students' understanding and progress, they can do it online such as using blog as an assessment tool. This study aimed to explore students' experiences in using blog as an online assessment by interviewing four students who were active using blog as an assessment tool. The findings showed that students used different ways in using blog as an assessment tool in terms of material they uploaded and the creativity in designing blog. Participating students found the challenges in using blog particularly in selecting the materials and designing the creative layout of the blog. The study highlights that blog can be used as an interesting assessment tool that explore teachers and students' creativity. Teachers need to have a goog understanding of the materials covered and the content that is understandable for the students.
\end{abstract}

Keywords: blog, online assessment, students, experiences

\section{INTRODUCTION}

Nowadays, teachers have flexibility to assess students' progress and achievement. They do not need to come to class to test students' understanding on previous materials. They can do the assessment online without necessarily coming to the classroom. This strategy is common for some teachers who are familiar and often use technology in their teaching practices. Particularly, for teachers who are very busy and have activities outside, applying online assessment is helpful for them. They can prepare the materials before the time for assessment and inform to the students the time that they can do the assessment. In this case, teachers can do the assessment although they are not in the spot, and with the help of technology this process is possible. In the literature, online assessment refers to assessing students' performances of their studies with the aid of Web-based technology (Hricko \& Howel, 2006; Petrisor, Marusteri, Ghiga \& Schiopu, 2011). As explained earlier, the test allows teachers and learners to have flexibility in the process of assessment particularly when the test is appropriate for both of them. The test is available anytime and anywhere so that the learners can maximize their preparation. They could also retake the assessment as necessary as possible and use the assessment result and feedback received to help identify the mistakes and improve their understanding on certain topics (Tsai, Tsai \& Lin, 2015). One of assessment tools that can be used in Blog. Teachers can use blog as an online medium in teaching and learning process. It refers to individual online journal which can update and revise using student's own words, ideas and this process enable students to explore their creativity (Petrisor et al., 2011). in using blog for assessment, teachers can design the content of the question according to the purpose of the test and students' needs. This allows teachers' creativity particularly in selecting the materials covered in the test as well as the type of questions used.

A number of study have investigated the use of blog in teaching practices within the context of EFL classrooms. For example, a study examined the use of blog in improving students' learning achievement and found that the use of blog helped ease students' understanding on certain topics (Mursidi, Murdani, Sumarli, Buyung, \& Rosmaiyadi, 2018). The students' understanding was represented by the increase of their score up to $75 \%$. Another study also found a positive effect of technology use in classroom practices. Hew and Brush (2007) identified that technology had impact on students' writing and reading skill particularly in providing a link and imagination for students to express their ideas. Even though both studies identified positive impacts of technology use in teaching practices, some teachers mentioned the barriers and challenges in applying the technology in the classroom such as selecting appropriate materials for the students, the time spent for preparation, and the facility that support technology use. The study indicated that the use of technology in teaching practices is helpful to make the teaching more interesting but the implementation of technological use should have meaning in transforming the information to the students. It is not only make the teaching enjoyable but students should understand the materials.

The present study aimed to identify the use of blog as an online assessment tool in EFL context. The use of blog as 
online assessment is not new for lecturers in English department of UIN Sunan Ampel Surabaya, one of Islamic university in Surabaya, East Java. The task that usually teachers ask to do is students create their own blog and complete the task according to the teacher's instructions. The tasks require students to upload materials online in their blog. In this process, students can learn others and they may have different ways in delivering the materials with the same task as instructed. This is the focus of the present study: identifying students' experiences when they create a blog as an online assessment from the teachers. In doing so, they may find some challenges or difficulties and this present study also examined the challenges students may face when designing blog. This present study different from previous studies in term of topic explored. Previous studies focused on the use of blog as tool to engage or improve students' learning and did not identify students' experiences when using blog. Thus, the finding of the present study may provide information on strategy use in selecting materials for blog within the context of EFL students. The study would inform other EFL teachers on how to design a blog as online assessment that students should do.

\section{METHOD}

To identify students' experiences in using blog as online assessment, this research used a qualitative approach by interviewing four EFL students. The qualitative method is appropriate to identify students' experiences in using blog as we could get comprehensive and in-dept information on how students design their blog and the challenges that they may face when designing the blog (Creswell, 2014). The four students were interviewed using semi structure interview in which the questions raise based on the guideline but researchers still have flexibility to add and develop questions according to participants' responses (Merriam, 1998). This process is important to ask clarification and justification of what participants said in the interview. So, the data obtained will be clear and comprehensive. We interviewed them for 30 to 45 minutes about their experiences in using blog and challenges they may face when doing the task.

As said earlier, four EFL students participated in the study. They were selected as they have taken CALL unit and have experiences using blog. There are four classes for CALL unit and this study involved one student in each class. Each student represents their class and CALL teacher recommended them to participate in the study. Before interviewing them, we informed them the purpose of the study and what they should do as participants. We also informed them that their participation was voluntary and they could withdraw their participation anytime without any effect on their score. We could also share the transcript of interview to them if they wish to check the accuracy of the interview data. We would keep the confidentiality of the participants and only the researchers who could access the data and know the name of the participants.
The data was analyzed using thematic analysis (Flick, 2014). At first, we transcript all interview data and read few times to familiarize the content of the transcript. While reading the transcripts, we highlighted the important points and gave notes based on the information raise in the transcript. The next step was combining the codes found based on the categories and themes. In categorizing the codes in some themes, we referred back to the research questions or area that we want to explore. Thus, every code found should be relevant to the topic explored. The themes are the data that appeared as the major findings in qualitative studies and these themes were often used as headings in the findings sections of study. Finally, we interpreted the data and explained systematically to answer the research questions.

\section{FINDINGS AND DISCUSSION}

The result of interview analysis indicated that students used different ways in designing blog by uploading varied English learning media such as: podcast, vlog, mind map, comic, online game, and, hot potatoes. When uploading the materials, students explained the function and use of each learning media to ease the readers. Interestingly, with the same task given from the teacher, students designed the content of the blog differently. For example, one student used pictures to describe family member accompanying with the video. Another student used a description of family members with a dialogue script. The questions raised was also different depending on the content of the materials uploaded in the blog. This finding indicated that the way students did depending on their creativity and experience on how to for example make readers understand the content of materials uploaded. Even though the two students explain the same topic that is 'family member', they describe the materials differently using two different learning tools (pictures \& video; text description \& dialog). According to them, in designing the blog they considered few things, namely: common materials or media used to make interesting learning, the familiarity of the media, and the easiness of media use. Student 3 and student 4 said that they prefered to choose common material to make interesting learning. Common here means the media that everyone knows an experiences using it in their classroom practices. For example, using dialog scripts with the video. Most of students may experience this learning process when they learn certain materials or topic discussed. However, the way students use dialog scripts may have different purposes depending on the target achieved. This process allows creativity particularly in selecting the materials that match with the intended purposes. Another example of activity they uploaded in blog was teaching simple present using comic description and teaching conditional sentences using game.

Another consideration in selecting certain learning media was familiarity with the media. Participating students believed that when they knew well how to use the media, it would be easy for them to create learning materials. As they already 
knew the function of media; what they required to do was matching with the learning objective. They could use different materials accompanying with the media they are familiar with. In uploading the materials in blog, all participants agreed that they should pay attention to the diction used to ease readers' understanding. As the material published globally, students needed to attract reader's attention to read. They should build readers' willingness to read texts or information in blog. The data analysis indicated that the way students wrote the information in blog using semi-formal writing style to avoid boredom and attract readers' interest.

In designing layout of the blog, students were free to explore their ideas. There were various ways in laying out the blog. First, making categorization of the blog content to make the reader easy to search the information. The blog consisted of several information including material, students' bio, references and learning media. All the contents were organised systematically. Another student organised the content without categorising to several sections. One student added an interesting sound in each button to attract reader's attention. Although four participating students were able to design the blog with different materials and media used, they said that it was not easy to design the blog. Using blog was not new for them but when combining the materials with considering the intended objective was not simple to do. All students agreed that the most challenges in designing blog as online assessment was providing description of media. They needed to understand clearly to be able to explain the function of media use. Another challenge identified was students' ability and knowledge about the blog, particularly for students who did have experiences using blog. They need to understand how to start and upload the materials in blog.

\section{CONCLUSION}

To sum up, this research showed that generally students know how to use blog as online assessment and they had different ways in choosing the materials, using learning media and describing the function of media used. In uploading the materials, they are aware that what they write should consider the readers' level of understanding. Therefore, they try to use the language that is understandable for everyone and make the layout easy for the readers. Students also consider the content of the blog that is engaging and interesting for the readers. Applying this approach could attract readers' interest to read. The study also identified some challenges in designing blog such as ability to describe the function of media used and choose appropriate layout of the blog. Although they admitted that they could design the blog, they still needed to learn more to be able to design blog effectively.

\section{REFERENCES}

[1] Creswell, J. W. (2014). Research design: Qualitative, quantitative and mixed methods approaches (4 ed.). California: SAGE Publications.

[2] Flick, U. (2014). An introduction to qualitative research (5 ed.). Los Angeles: SAGE Publications.

[3] Hew, K., \& Brush, T. (2007). Integrating technology into K-12 teaching and learning: Current knowledge gaps and recommendations for future research. Educational Technology Research and Development, 55(3), 223-253.

[4] Hricko, M., \& Howel, S. L. (2006). Online assessment and measurement: foundations and challenges. Hershey, PA: Information Science Publishing.

[5] Merriam, S. B. (1998). Qualitative research and case studies applications in education. San Fransisco: Jossey-Bass Publications.

[6] Mursidi, A., Murdani, E., Sumarli, Buyung, \& Rosmaiyadi. (2018).

[7] Role of Whatsapp aplication in building the interests of student literacy. Paper presented at the The 2nd International Conference on e-society, eeducation and e-technology, UIN Ar-Raniry Banda Aceh.

[8] Petrisor, M., Marusteri, M., Ghiga, D., \& Schiopu, A. (2011). Online assessment system. Applied Medical Informatics, 28(1), 23-28.

[9] Tsai, F.-H., Tsai, C.-C., \& Lin, K.-Y. (2015). The evaluation of different gaming modes and feedback types on game-based formative assessment in an online learning environment. Computer and Education, 81, 259269. 